\title{
Erratum: Performance Analysis of Handover TCP Message in Mobile Wireless Networks
}

\author{
Ashutosh $\mathrm{Kr} \mathrm{Rai}^{1}$ and Rajnesh Singh ${ }^{2}$ \\ ${ }^{1}$ Shobhit University, Meerut, India \\ ${ }^{2}$ Rajnesh Singh, Manav Bharti University, Solan, India \\ akrai.iimt@gmail.com, rajneshcdac.mtech@gmail.com
}

S. Aluru et al. (Eds.): IC3 2011, CCIS 168, pp. 254-261, 2011.

(C) Springer-Verlag Berlin Heidelberg 2011

DOI 10.1007/978-3-642-22606-9_63

Due to a serious case of plagiarism this paper has been retracted.

The paper "Performance Analysis of Handover TCP Message in Mobile Wireless Networks" < http://www.springerlink.com/content/h12j112777784247/> appearing on pages 254-261 of this publication has been retracted due to a severe case of plagiarism. 